\title{
HOW TO MAKE GOVERNMENT AGILE TO COPE WITH ORGANIZATIONAL CHANGE
}

\author{
Yvonne Dittrich \\ Jan Pries-Heje \\ Kristian Hjort-Madsen \\ IT University of Copenhagen \\ Copenhagen, Denmark
}

\begin{abstract}
In Denmark, the largest organizational change project with information technology ever is being shaped. By January 2007, all counties and municipalities will be reorganized. More than I million employees will be affected, and all public IT systems will have to change. To make this huge change project a success, agility is needed.

In 2003, a kind of pilot study for the coming change project was undertaken. Five municipalities on the Island of Bomholm merged. In this paper, we report on the merging process--especially the IT diffusion-through an indepth interview study.

Our analysis of the interview data leads us to suggest five means in order to make the Danish government agile enough to cope with the upcoming major reorganization. First, the organizational change should be integrated and aligned with the IT change. Second we recommend an early start. Third, an IT vision is needed. Fourth, we recommend a rethinking of the existing public service provision. Finally, we see a need for new tools and techniques. Together we believe these five means, if implemented throughout the Danish government, will create the agility that is needed to cope with the major organizational change by 2007
\end{abstract}

Keywords: Agility, design in use, eGovernment, mergers, organizational change, user empowerment

\section{INTRODUCTION}

A bill has recently been passed in parliament that will result in a total reorganization of the county and local levels of government in Denmark. The idea is to decentralize 
more government responsibility which requires that local units have the size to take on the added responsibility. By January 1, 2007, it is expected that the existing 271 municipalities will be merged into 100 and the current 14 counties will be amalgamated into five regions. Furthermore, it is suggested that all of the new municipalities should have one entry point for the citizens, for example, in the form of a one-stop citizen service. The Danish government is, therefore, forced to develop a strategy for the convergence of all of the affected IT systems that is agile and ready to adapt quickly to changes while also sensitive to the diffusion of new IT. Thus we believe that the balance between agility and diffusion of information technology will become a key issue for the Danish government when it undertakes the largest structural reform in 30 years.

A kind of pilot project for the structural reform was undertaken in 2003 on the Danish island of Bornhol $\mathrm{m}$ with the merging of five municipalities and one county into the Regional Municipality of Bornholm. With regard to the structural reform in Denmark, we believe that a lot can be learned about agility, organizational change, and IT-diffusion from the process that Bornholm went through. Bornholm started out with no prior experiences for a benchmark and the process was expensive and very stressful for the employees.

In this paper, we report first results from an interview-based case-study focusing on change management and the development of work practices. We emphasize learning that can be used in the reorganization of the Danish municipalities mandated for 2007. We relate our findings and measures to the literature on agility, organizational change, work practice, and technology.

The remainder of this paper is laid out as follows. Section 2 of this paper discusses relevant theory on agility, change, and design in use. Section 3 introduces the Bornholm case. Section 4 lays out our research method. Sections 5 and 6 details our findings from analyzing our findings on organizational change and on design in use, and section 7 discusses the case findings in relation to agility. Finally, in section 8 , we identify the challenges faced by the Danish government and the 100 upcoming amalgamated municipalities, and discuss how they can become agile enough to cope with the changes they are facing.

\section{AGILITY, CHANGE, AND DESIGN IN USE}

The discussion on agile organizations and agility in development relates management of organizational change and the development of practices that help implement the changes as part of day-to-day work. For analyzing the merger on Bornholm, we have developed an analytical framework combining the existing literature on agility with a top-down organizational change perspective and a bottom-up work practice perspective.

The joining of municipalities can be seen top-down as an organizational change process. When we go inside the organization and come closer to the individual adoption of the organizational change and IT, we can take a bottom-up point of view and look at it as work practice and design in use. 


\subsection{Agility}

The discussion of agility is, on the one hand, addressing organizational change and management issues, while, on the other hand, emphasizing the importance of practices and technical support that help the people in an organization to handle change.

In this section, we will identify characteristics of agility with the purpose of developing a framework that can be used to analyze our case.

According to the Oxford Advanced Learners Dictionary Web site (http://www.oup. $\mathrm{com} / \mathrm{elt} / \mathrm{oald} /$ ), lean means thin and fit or containing little or no fat. However, it can also mean "strong and efficient." According to the same dictionary, agile means that you are able to move quickly and easily or that you are able to think quickly and in an intelligent way.

Lean manufacturing is a term that grew out Japanese production methods where the focus is the absolute elimination of waste. This is implemented by just-in-time production where a process withdraws only the number of parts needed when they are needed. Recently agile manufacturing (Newman et al. 2000) has become widely accepted. Agile manufacturing regards an ability to conflate flexible manufacturing and component reuse. Flexible manufacturing is an ability to reconfigure a manufacturing system quickly and cheaply to assemble a varying part mix. Agility invokes a design philosophy that includes reuse and enables rapid redesign for entirely new applications. Thus the first characteristic of agility that we will use in our analysis is rapid redesign.

Dove (2001) defines agility as something more than rapid redesign and flexibility. He defines agility as both a physical ability to act, called response ability, and the intellectual ability to find appropriate things to act on, which he calls knowledge management. The first part of this definition is cognate to what we have called rapid redesign and flexibility. He just calls it change proficiency and "reusable/reconfigurable/ scalable" structural relationships that enable change. The second part, however, is new. Dove divides the knowledge management part into knowledge portfolio management and collaborative learning facilitation. We will use this part of Dove's definition of agility as our third characteristic: knowledge management and learning.

What types of knowledge are we then talking about when discussing changes in an organization heavily dependent on IT? A few years ago Kensing and Munk-Madsen (1993) build a model of user-developer communication. The model covers communication related to analysis and design of IT. It claims that the main domains of discourses in design are (1) users' present work, (2) technological options, and (3) the new system. The hypothesis is that knowledge of these three domains must be developed and integrated in order for the design process to be a success. Thus when we analyze our Bornholm case for agility, understood as knowledge management and learning, we will use the three discourses to do so.

The third characteristic we will use is flexibility, meaning that one is able to change to suit new conditions or situations. The importance of flexibility in developing software for rapidly changing business environments is well recognized in software development especially for Internet applications (Aoyama 1998; Baskerville et al. 2001). Agility in software development refers to the ability to not only quickly deliver the products, but also the ability to quickly adapt to changing requirements (Aoyama 1998). What we can learn from the discussion on agile development is the emphasis on concrete, everyday 
work practices that support the flexibility of an organization as well as well-developed and maintained infrastructures and tools that support those practices

The discussion on knowledge implicitly points to the role of the people involved in the change. In relation to software engineering, the term agility was introduced in 2001 when a group of people involved in finding, testing, and defining new methods meeting at a skiing resort in North America came up with an agile manifesto (Agile Manifesto 2001):

We are uncovering better ways of developing software by doing it and helping others do it. Through this work we have come to value: (1) Individuals and interactions over processes and tools. (2) Working software over comprehensive documentation. (3) Customer collaboration over contract negotiation.

(4) Responding to change over following a plan.

Following this line of thought, the fourth and final characteristic that we will call agility is whether individuals are prioritized over processes and standards.

\subsection{Organizational Change}

Agility of an organization has to do with change and the management of change. Organizational change in relation to IT is still attracting considerable attention. Dunphy (1996) studied organizational change in corporate settings and found that any theory of change should incorporate at least a metaphor of the nature of the organization, an analytic framework, an ideal model of an effectively functioning organization, an intervention theory, and a definition of the role of change agents.

Three different schools of organizational thought have provided metaphors of the nature of the organization. The oldest approach to organizational design and change builds on the belief that you can identify the one best way of carrying out any job. The organization is perceived as a production system where it is possible to optimize the system's efficiency and effectiveness. In the 1930s and 1940s, the classical view of organizations was challenged and a new people-oriented perspective, rather than a mechanical one, emerged, where organizations are seen as cooperative social systems that allow people to meet their emotional needs. So the metaphor for an organization is a (large) group of people with a culture among them and visible communication and interaction processes between them. The third school of thought has been called the political-emergent perspective (Borum 1995; Burnes 1996). It is characterized by the belief that organizations and change are shaped by the interests and power struggles between special-interest groups or coalitions.

It is possible to combine tools and techniques from the three different perspectives. Kotter (1996), for example, recommends eight stages in leading a change process: (1) establish a sense of urgency, (2) build support, (3) develop a change vision, (4) communicate the change vision, (5) empower and enable action, (6)generate shortterm wins, (7) consolidate and revitalize change, and finally (8) anchor new approach in culture. The first, third, and fourth of these stages are close to the view of an organization as a production system, whereas the second, sixth and eighth stages clearly show 
the organization as a social system. The second and fifth stages are take power and special interests into account (see Kotter and Cohen 2002).

Organizational change processes can rarely be considered a linear function (Weinberg 1997), and often the best change strategy is to keep as much stability around the change as possible simply to allow enough energy and attention for the people changing behavior.

\subsection{Design in Use}

The third analytical perspective we apply allows us to focus on the concrete work practices. This perspective tries to understand the interaction and mutual dependencies between the actual work practices and the structures, procedures, and technologies that are implemented and used by it. Organizational structure and technology are not seen as something stable and fixed, determining what actually goes on, but something that is subject to ongoing interpretation, negotiation, and adaptation.

Suchman (1983) describes office procedures as results of practical action. Analyzing the handling of a past-due invoice, she shows that what on the surface can be regarded as an orderly procedure is in fact constructed through the work practice of the administrators involved. Likewise Gerson and Star (1986) show that organizational processes are never fixed. In fact the continuous maintenance of processes and structures used as basis for decisions requires articulation of developments, constraints, interests and consequences. In the health insurance company analyzed by Gerson and Star, this "due process" is placed with a committee specifically designed for this task. Computer systems both mirror the result of due processes and provide constraints for ongoing negotiation and redesign.

Although many have the impression that governmental decision making is guided by rules, Lenk et al. (2002) use a case of a single parent asking for social benefit to show that, in practice, the application of rules does not explain reality. Dittrich et al. (2003) studied the introduction of new technical support for municipal service provision and found that the development of service provision practices results in adaptation and changes of the technology used. Such practices of "design in use" indicate that at least the less-formalized aspects of service provision (Lenk et al. 2002) are subject to due process and articulation work as are similar processes in office work in private companies. Additionally the legal base for decision making changes quite frequently. To understand better how the specific organization-or reorganization-of service provision and the design and use of the technology interacts, close-up studies and analysis of the role that technology plays in the service provision is needed.

\section{CASE: BORNHOLM}

Bornholm is a smaller Danish island with 45,000 inhabitants situated in the Baltic Sea. In January 2001, the mayors from the five municipalities on Bornholm met. The result of their meeting was a suggestion for a local election about the amalgamation of the five existing municipalities on the island. 
The background for this suggestion was a local debate that had been going on for some time. It was often claimed that having five very small municipalities in such a limited geographical area led to both economic and democratic ineffectiveness.

The five city councils supported the election with great majority and a local election was held in May 2001. A total of 74 percent of the island's population voted yes to an amalgamation of the five municipalities. It was decided that a new regional municipality of Bornholm should be effective from January 2003.

\section{RESEARCH METHOD}

A little more than a year after the amalgamation, or merger as we will call it in the remainder of this paper, we conducted an in-depth interview study focusing on the outcome of the Bornholm merger. The purpose of the study was to reconstruct and understand the complex merging process in order to identify lessons to be learned.

We decided to interview users and IT professionals from Bornholm as well as developers from KMD, the semi-public provider of IT. To capture both management and shop floor perspectives, we interviewed representatives from all three groups. We interviewed 12 people. Eight of them were from Bornholm, of which half were IT people and the remainder IT users primarily from the "one-stop shops," single points of access to the citizen services that were introduced and placed at the former town halls as part of the change process. One-stop shops deal with more or less any issue a citizen may bring.

Of the remaining four people interviewed were three from KMD and one from the Danish Federation of Municipalities. Table 1 gives an overview of our interviewees. For the purpose of anonymity, we have changed everyone's name and used city names from the island of Bornholm as pseudonyms.

We asked the interviewees to reflect on their experiences with the merger. We supplemented the interviews by examining artifacts-documents, presentations, and newspaper clippings--from before and after the merger.

Typically all three authors conducted the interviews. One of us concentrated on having a good dialogue and making sure that all the issues in our semi-structured interview guide were covered, while the other two took notes. Furthermore, all of the interviews were taped, and central parts from each interview were transcribed and summarized for detailed data analysis. Formally, our research method can be described as an in-depth case study relying on data triangulation (Yin 1994).

The interview notes including the transcribed parts were then analyzed in an iterative hermeneutic process. This revealed six interesting lessons, three on the change process itself, and three on the design process. In the two next sections we will lay out our findings.

\section{LEARNING FROM THE CHANGE PROCESS}

This section takes the top-down perspective looking at the organizational change process that took place at Bornholm. 
Table 1. An Overview of Our Interviewees

\begin{tabular}{|l|l|}
\hline \multicolumn{1}{|c|}{$\begin{array}{c}\text { Name } \\
\text { Pseudonym) }\end{array}$} & \multicolumn{1}{c|}{ Organization and Role } \\
\hline Anne Arnager & $\begin{array}{l}\text { Employed since 2000. Works in the one-stop citizen service in } \\
\text { Rønne, the largest city on Bornholm. Gaya Gudhjem is her } \\
\text { superior. }\end{array}$ \\
\hline Berit Balka & $\begin{array}{l}\text { Employed since 1988. Works in the one-stop citizen service in } \\
\text { Nexø, the second largest city on Bornholm. }\end{array}$ \\
\hline Diana Dueodde & $\begin{array}{l}\text { Employed with KMD, the semi-public supplier of IT. } \\
\text { Responsible for development support. Headed the steering } \\
\text { committee on behalf of KMD }\end{array}$ \\
\hline Gaya Gudhjem & $\begin{array}{l}\text { Employed since 1989. Chairman of the group that looked at } \\
\text { debtor IT systems for collecting money. }\end{array}$ \\
\hline Heidi Hasle & $\begin{array}{l}\text { Employed since 1976. Worked with property tax collection in } \\
\text { Rønne. }\end{array}$ \\
\hline Nils Nylars & $\begin{array}{l}\text { Responsible for all IT development in the new regional } \\
\text { municipality. }\end{array}$ \\
\hline Mikael Myreby & ClO for all IT in the new regional municipality. \\
\hline Ole Olsker & $\begin{array}{l}\text { Senior consultant from the Danish Federation of Munici- } \\
\text { palities. Visited Bornholm many times throughout the } \\
\text { merging process. }\end{array}$ \\
\hline $\begin{array}{l}\text { Ron Rutsker and } \\
\text { Soren Sandvig }\end{array}$ & $\begin{array}{l}\text { Both employed with KMD. Responsible for some of the } \\
\text { specific development of estate and taxing systems. }\end{array}$ \\
\hline Teo Tejn & Works with debtor systems and tax collection in Rønne. \\
\hline Viggo Vang & \begin{tabular}{l} 
Employed in the IT department. Reports to Mikael Myreby. \\
\hline
\end{tabular} \\
\hline
\end{tabular}

Because the politicians on Bornholm prioritized a rather long period for political discussions about the organizational setup of the new regional municipality, the execution phase for the IT part of the merger was very short. During the planning phase after the election in May 2001, 22 working groups were formed, one of them focusing on IT. But the working groups were only supposed to map out, describe, and identify problem areas. They were told not to make any major decisions with regard to the future organization of the IT organization in the new regional municipality of Bornholm because this was seen as a political decision. "Up to the election of a new regional council on May 29, 2002, everybody was told not to do anything," said Mikael Myreby. To people from the outside, this was experienced as decision avoidance. Ron Rutsker and Soren Sandvig, from KMD, experienced this as a lack of decision power. They said, "We experienced a kind of decisional vacuum. Nobody knew who was to answer what."

Another related problem was ignorance of how much a change process actually implies. For example, it requires a lot of extra time, but that time wasn't allocated. Gaya Gudhjem said, "No time was set aside specifically for the development work. Thus we 
didn't have time to really advance as we should have. There were things that just hobbled along."

By January 1,2003, the amalgamation was done and only one regional municipality existed on Bornholm. But in fact a lot happened right after that New Year. For example in the local tax administration, property tax bills were sent out twice. We were told that some people actually paid twice. A lot of work to redo the property tax collection manually was required. Anna Arnager gave us about another example where a person called in very mystified that he shouldn't pay tax:

We had a case where a person called because he hadn't paid property tax. We checked it in the system, but his tax was actually paid. Then we looked more deeply into it and found that the tax was paid through an Internet bank. The man declined that he had paid via Internet and when we checked we found that a total stranger had paid the tax for this man using his old debtor number. From that we learned never to reuse debtor numbers.

\subsection{Non-Flexible Empowered Employees}

The election for the new Bornholm city council took place in May 2002, but the new council did not make any decisions before the summer holiday. After summer, the contract between Bornholm and KMD was finally signed and the work in the 22 working groups restarted - it had been stalled for a long period due to the request to not make decisions. However, many of the people participating in the working groups were still hesitant to make decisions because they didn't know their own role in the future. Viggo Vang said, "The users were not involved in the whole merging process. The reason being that it was not decided where each individual would be Igeographically and job wise] after the merger."

The only thing the employees knew at this point was that everything would change: the organization, their job, and probably their geographical location (to another town most likely). This caused a lot of uncertainty and a lack of willingness to make important decisions. Nils Nylars said,

At this time we did not know our future organization; neither did we know what goals to pursue. That is the reason why most of the work came down to discussing the conversion of data. We didn't know who was going to work with the systems. And we didn't know anything about the interfaces [between people and systems]. For example we did not know whether there would be a one-stop citizen service in the new regional municipality.

However, in a few places it was actually known very early who was to have which job after the merger. For example, this happened in the unit responsible for tax collection. "Everybody knew who was going to be director of that company [municipal unit]. Therefore they were in charge," Mikael Myreby said.

Users were expected to take responsibility for the restructuring, but in reality KMD took over the design of the new systems because the working groups were not able to make decisions. 
The workers in the different working groups had been empowered to map out the existing processes. Berit Balka, who had a job in the information desk before the merger, said,

Before the merger we met every 3 months and tried to unify and standardize our work processes. So we meet and we told what pictures [referring to screens] we needed. These meetings continued until Christmas at which point we were told which job we were going to have.

So the first result of our analysis of the interview data is that the IT system users were expected to take responsibility for the restructuring, but in reality KMD was setting the agenda. So the "empowered users" lacked flexibility to imagine something for others than themselves.

\subsection{Too Much Change at the Same Time}

As we said above, the working groups were not able to make actual IT decisions before the end of 2002. In fact, the initiation of the new amalgamated IT function happened in October 2002, but the first couple of months they turned inward and concentrated on defining an IT strategy. "We used all of October and November to write the IT strategy," said Viggo Vang.

Mikael Myreby emphasized that the late establishment of the new IT organization created huge problems: "The reason being that everything from IT systems to the intranet was new." Thus it seems that the lack of time for the execution phase dramatically increased the cost of the merger.

Another problem identified in our analysis was that it was expected that savings from the merger would materialize more or less immediately. Unfortunately that was not the case. Diana Dueodde said, "Bornholm did not harvest any savings in the beginning. You don't do that from day 1."

The official figure for the costs associated with the Bornholm merger was more than eight million U.S. dollars (using a 6-to-1 currency exchange rate). We received access to the data behind this figure and found that it only included money for IT investments and some of the working time before and after the merger took effect on January 1 , 2003. We present the main figures in Table 2.

However, our interviews clearly told us that considerable time was invested in the change process after the merger (i.e., to define and agree on how to work in the new organization). Formally this wasn't accounted for as extra time but in fact it was time that was not used to service the people on Bornholm. Even when we visited 18 months after the merger, there were still new processes related to the merger that were being discussed. Our best estimate is that the merger may have had costs up to 50 percent more than are shown in the official figures (Table 2).

It was not that people were not trying to cope with the many changes. The head of IT development, Nils Nylars, told us: "You have to prioritize the changes. You only have limited energy. We reached a point here where the employees said NO, now we cannot take any more change. We need a project stop." 
Table 2. Costs in Relation to the Merger on Bornholm (All figures are converted to U.S. dollars)

\begin{tabular}{|c|c|c|}
\hline & 2002 & 2003 \\
\hline Merging committee & $1,364,901$ & \\
\hline $\begin{array}{lr}\text { Integrating IT systems } & \\
\text { Converting KMD systems } & 1,818,792 \\
\text { Dental Care system } & 21,313 \\
\text { Ramboel Care } & 468,167\end{array}$ & & $2,308,272$ \\
\hline IT investments & 613303 & 833,732 \\
\hline Establishing a common telephone system & & 265,396 \\
\hline Moving costs & & 356,367 \\
\hline Extra income to politicians & & 246,333 \\
\hline Total & $1,978,204$ & $4,010,100$ \\
\hline
\end{tabular}

We believe that the real problem was that too much was happening in the same very short time period. Gaya Gudhjem told how she experienced the merging process: "It was not the merging of the systems that was worst. It was the merging of cultures. And it was whether I got the table [here referring to whom was getting which job after the merger]." And she continued, "The biggest change from before to now is the culture. And the people that worked alone before had the worst experience. Suddenly they needed to cooperate."

So our second result from analyzing the data is that too much uncoordinated change at the same time dramatically increased the cost of the merger.

\subsection{No Clear IT Vision}

Although a clear vision of how to organize the new regional municipality so every organizational unit became an independent company existed, IT was discussed surprisingly late in the merging process. Even though the merger was agreed upon almost two years in advance, the IT part of the merger was only seriously considered half a year before the actual merger and executed in the last couple of months in 2002.

After the clear public support in the ballot for the merger, the legal foundation for the new regional municipality was negotiated with the central government, and later accepted by the Danish national parliament with the introduction of a new law on the merger. The local preparations for the merger started mid-2001. But neither in the central negotiations between the Ministry of the Interior and Bornholm nor in the local preparation work on Bornholm were the IT challenges seriously discussed before the middle of 2002. IT was simply not considered an important, nor problematic, part of the merger.

After the merger, one of the largest problems on Bornholm was that the IT changes were perceived as a simple data convergence task. Maybe because all of the five existing municipalities were primarily using an IT system provided by KMD they did not 
perceive the IT integration challenges to be very large. Furthermore, IT challenges were considered a problem for the IT provider and consequentially not a large issue in the merger. Mikael Myreby said,

All the five municipalities on Bornholm were KMD customers, and from the beginning there was a belief that everybody could just use the systems from Rønne [the largest of the five municipalities]. However, it turned out that all the municipalities have had different organizational structures and as a result of that; used the KMD-systems differently.

And Ron Rutsker and Soren Sandvig, from the IT supplier KMD, said,

In the user tests, we clearly experienced that there were different ways of doing things [in the five municipalities]. Especially the BGS system [used to identify a specific estate in a building file] was used differently. Some used a threedigit number [for referring to a building] while others just referred to a name such as Meadow Farm.

One problem that came out very clearly in our analysis was that the carefully described processes didn't work out. The head of IT development in the new organization, Nils Nylars, said,

At the point in time where we created the workflow descriptions people perceived things as they were in the old system. As of today [August 2004] we haven't had time to envision a unified way to work. The first year after the merger was just pure survival.

Another problem was that energy was used for the wrong things in the new organization. Nils Nylars said,

As a manager you have to remember that the employees are used to collecting money. They know how to do that. They just do it different ways [in different municipalities]. So we have learned that we should have focused much earlier on the new way of doing things-the vision for how to cooperate in the future. That lesson surprised us, but it is very clear for us today.

According to Kotter (1996), a vision is needed in a change process to motivate, to show direction, and to help in coordinating and integrating action. Thus the third result of our analysis is that a clear and communicated vision of how to integrate the differing work procedures and the deployment of IT was lacking in the Bornholm merger.

\section{INTRODUCTION OF ONE-STOP SHOPS: REDESIGNING SERVICE PROVISION}

This section takes the bottom-up perspective looking at the Bornholm case from a work practice and design in use perspective. We start in the one-stop shops as they 
provide an example of the necessity to redesign municipal service provision when merging different municipalities. Four of old city halls were closed. Instead, one-stop shops have been introduced to provide the municipal services for the citizens.

The one-stop shop in Rønne is situated in a large, open-plan office that before the merger had already welcomed the visitors of the city hall. Visitors still meet the information desk and the cash counter when entering the city hall. For specific advice, they turn to the one-stop shop personnel whose desks are turned to meet visitors. The back office units situated in the same building also still man front office desks in the open area. The specialists working there take care of requests regarding their specific area. As Rønne is the biggest of the former independent city halls, it hosts quite a few of these units. The employees have the possibility to occupy separate offices in case the request and support is of a more private character. Most of the one-stop shop employees in Rønne also work with other tasks, mainly debt-collecting business, as this part of the municipal services belongs to the same unit.

Although working with similar tasks, the one-stop shop in Nexø is organized differently. A counter in the reception areas provides space for two employees. Behind the counter, a number individual desks are placed, providing space for more concentrated work at the computer and for longer consultations with the citizens. A small office is provided in a corner, to allow for privacy and to provide a workplace for specialists from other units who visit Nexø for appointed meetings with citizens. Nexø was one of the smaller municipalities that earlier had been dominated by the fishing and fish-processing industry. Today it hosts an internationally reputed design school. The Nexø one-stop shop, therefore, handles more issues concerning foreigners, visas, and permits of residence than any of the other of the one-stop shops on the island.

When we performed the interviews the different lay-out, culture and character of the 2 one-stop shops became visible. Internal organizational specificities, local and demographic differences, and previous experiences of the personnel staffing the onestop shops influence the distribution of tasks, the development of expertise, and, with that, the organization of service provision and requirements regarding computer support. So it would be interesting to visit the municipalities in another two years and see how the situation developed further.

Our analysis revealed three aspects that seem especially relevant.

\subsection{Poor Integration of Organization and IT Infrastructure Development}

Among the municipal workers, the one-stop shop employees probably were the worst prepared for the change awaiting them. As no one-stop shop existed previously, no experience with such an organization was provided. The majority of the employees we interviewed did not choose the one-stop shops as their new work place, as nobody understood the requirements for this kind of work.

Only three weeks before switching to the new organization, the employees received the information about their new work place. The necessary training took place parallel to starting up the one-stop shops and was still going on when we performed the interviews (in August 2004). There was no time or place to think about necessary IT 
support beforehand, as the working groups preparing the data integration and the implementation of the software configurations were organized according to the traditional sectors of municipal service provision. There was no time or place for the preparing "articulation work" (Gerson and Star 1986).

The introduction of the one-stop shops is an example for our fourth finding, that the development of the organization and the development of the supporting infrastructure were not well integrated. In other sectors, this contributed to a lack of willingness of the employees to take decisions on behalf of others. In respect to the one stop shop, it led to a lack of IT support as discussed in the next section.

\subsection{No Appropriate IT Support for One-Stop Shops}

One-stop shops are meant to provide access to all municipal citizen services. Their introduction clashes with the traditional organization of computer support for public service provision. The computer systems supporting municipal administration in Denmark are provided centrally by KMD. The data is accessed via rather traditional mainframe terminal interfaces using commands consisting of character-number combinations for navigation. Taking over the front office tasks and consulting with the citizen on a wide variety of issues implies that the employees are using many of the different systems that are designed to support the service provision in the different units. One of the difficulties for one-stop shop workers is to navigate between and within the different systems that are optimized for personnel working only with the respective area. The largest difficulty in the beginning, therefore, has been to remember all the codes, as several of our interviewees emphasized, to learn the commands to access the data the different systems provide.

Although the sector-specific procedures and information access are documented in a set of folders, this information does not help much in everyday work. For example, Berit Balka said, "If there is a woman coming in who has decided to divorce from her husband, and needs a flat and has to sell a house and needs social benefit, you just cannot take a folder and read up on what to do." Therefore, they developed a customized work folder where they collect the most important short cuts and other necessary information. One-stop shop work relies heavily on a set of practices: "When somebody comes with need for support I always first do an A1850 on the person to get the basic data and see whether they have been in contact with the municipality before" (Berit Balka).

The new organization of the service provision on Bornholm is not supported by the organization and architecture of the software systems. Also the sector-specific documentation of procedures does not fit. Making things work with IT that does not fit or no IT support has been one of the stress factors in the merger. The introduction of one-stop shops requires a rethinking of service provision, but also a rethinking of the IT support for municipalities.

This, however, is not a straightforward task. The way computer support for municipal service provision has developed in the past implements a sector-specific organization of the service provision. Although the data is integrated behind the scenes leading to a net of dependencies on the server side, the access to these mainframe 
systems - which even the IT department of Bornholm perceives as black boxes-is organized sector-wise. Client-side integration with other local systems is possible but often results in partial duplication of the data and delayed update of the mainframe data. For example, local administrative systems for the organization of home care updates the central state register which is then used to update the mainframe side of the abovementioned municipal software provider. "It can take up to two days before this data is accessible for other units of the municipal administration," as Viggo Vang explained.

So our fifth finding from our analysis is that the traditional IT support does not fit with the one-stop shops cutting across traditional sectors of municipal service provision.

\subsection{No Means for Discussing and Designing the IT Infrastructure}

Designing the IT infrastructure is an issue that is not just relevant for the mainframe systems, which are described as black boxes or as screens that are accessed through codes. Besides those, the one-stop personnel rely heavily on the central server providing online forms and instructions on how to fill them out, and the municipal telephone exchange that contains information about all employees, their tasks, and a individual calendar system that shows whether and when each employee is available. To forward case-specific questions that cannot be solved by accessing the data in the respective application or for getting advice regarding a more complicated case, they rely heavily on being able to contact the respective case worker or expert responsible. One of the major hazards, especially for the one-stop shop personnel, was that this new telephone system did not work in the beginning. Besides this main support, a set of other systems is used: the cashier system, as citizens can pay different fees and even taxes in Sweden directly to the city hall, the e-mail system for communication, and the extra- and intranet are just a few examples.

To consciously plan the reorganization of services together with the reorganization of the necessary design of information systems, one would need some way of describing the presently used technology and planing how to organize future IT support. Such design artifacts and methods would not only be necessary for major reorganizations, but might provide support for the ongoing negotiation and continuous design of the service provision in the two one-stop shops, for the due process (Gerson and Star 1986) of municipal service provision.

Neither the software as it is designed today, nor the development processes support the design in use that takes place when information technology is used not only as a data repository but as support for service provision. To support a more flexible and agile organization of service provision that, on one hand, becomes possible with today's network and Internet technology and that, on the other hand, is required when merging municipalities, the traditional software support has to become itself more flexible and adaptable.

So our sixth and final finding is that one of the reasons why users during the Bornholm merger did not involve themselves in any discussion of IT infrastructure was that they simply had no means to discuss changes in the infrastructure. 


\section{DISCUSSION}

The analysis sections 5 and 6 resulted in complementing but in some cases also contradicting causes for what many of the participants perceived as a problematic change process. From a change management point of view, we found that empowered employees nevertheless were non-flexible. We found that too much (uncoordinated) change at the same time dramatically increased the cost of the merger. And we found a lack of a clear and communicated IT vision.

The bottom-up focus on the introduction of and the developing work practices in the one-stop shops led to the conclusion that there was a lack of coordination between the organizational change and the development of IT infrastructure. We found that the traditional IT support didn't fit with the one-stop shops cutting across traditional sectors. And we found missing means to discuss changes in the IT infrastructure.

\subsection{Remedies to Cope}

As the problem analysis differs, the remedies that can be identified differ as well: The increase in cost and time because of too much change at the same time can be countered by careful planning, allowing enough room for one change at a time (Weinberg 1997).

The way to cope with non-flexible but empowered employees would be to build an environment for the individuals that leads them to take responsibility for defining and discussing tasks, and work flows that they themselves will not have responsibility for after the change.

The lack of a clear and communicated IT vision leads, of course, to the need to define and communicate a vision and make expectations clear from day one (Kotter 1996).

The lack of coordination between the organizational change and the development of the IT infrastructure can be met with active integration of both dimensions of change. This would probably address the problem of too much uncoordinated change as well. If changes can be perceived as meaningful complements, the tolerance for change might be higher. Also an early decision regarding the placement of employees could clarify their mandate regarding decisions on the future IT support. Such coordination would be supported by a vision of how to use IT in the future organization, but the concrete development would probably change the initial vision as things evolve.

One-stop shops cutting across traditional sectors are one way to implement the single point of access to municipal services that the new law requires. However, they question the traditional sector-specific organization of municipal service provision, and require a different kind of support. To develop support that better fits, it should also be adjustable to local specializations as they becomes visible. When comparing the two one-stop shops we visited, one would need a means to not only discuss single applications but also their interaction. Space and time for articulation work has to be provided (Gerson and Star 1986). 


\subsection{Discussing Agility}

In section 3, we defined an agility framework with the following characteristics: (1) the ability of making rapid redesign, (2) flexibility, understood as being able to change to suit new conditions or situations, (3) knowledge management in relation to users' present work, technological options, and the new system, and (4) whether individuals are prioritized over processes. If we now take a look at our suggested measures to cope with the problems identified in the case we can ask: How are our suggestions related to agility? In Table 3, we have given an answer simply by comparing each of the six Bornholm lessons and their remedies against each of the four characteristics of agility.

The proposed remedies from an organizational change perspective in themselves do not comply well with our four characteristics of agility. However, when we combine the measures proposed with a work practice-oriented analysis, then the picture changes. For example, measure 4 can also be seen as a remedy for too much uncoordinated change. Here the work practice perspective allows for a different interpretation of the same phenomenon leading to a recommendation supporting the agility of an organization. Understanding measure 3 as a support for the coordination of organizational change with the development of the IT infrastructure allows us to see the contribution of a seemingly top-down and inflexible instrument to the flexibility of an organization. The frustration of the one-stop shop workers over the failure of the technological infrastructure to work indicates that one way to strengthen individuals in coping with change is to provide suitable support.

Interpreted that way, the measures we suggest are in good accordance with the four characteristics of agility. So it is fair to say that we recommend that the changes in of government about to take place in Denmark need a transformation to agile.

\section{CONCLUSION}

From a scientific perspective, the conclusions in this paper are that it is necessary to relate government agility to an analytical perspective that focuses on the deployment of technology in the concrete work practices in addition to one on organizational change processes. The paper has demonstrated the importance of taking on a proactive approach to the major integration challenge that awaits in 2007 . Only by becoming agile can the largest public change project ever undertaken in Denmark succeed.

The interesting thing about the Bornholm case is that it is a kind of pilot for the hundreds of similar projects about to take place starting on January 1, 2007. So a highly first relevant question is: What can be done to avoid the problems we identified at Bornholm? Based on our analysis, we propose the following:

- Actively integrate the reorganization of the municipality with the design and development of the infrastructure.

- Start early to have time for these activities and to be able to decide on changes with enough time. 
Table 3. Comparing Our Six Suggested Measures with Characteristics of Agility

\begin{tabular}{|c|c|c|c|c|c|}
\hline Results of Analysis & $\begin{array}{l}\text { Requirements to the } \\
\text { Agile Organization and } \\
\text { IT Infrastructure in the } \\
100 \text { New Municipalities }\end{array}$ & 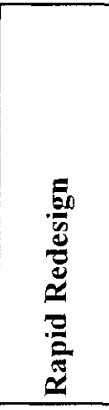 & $\frac{2}{\frac{2}{2}}$ & 范 & 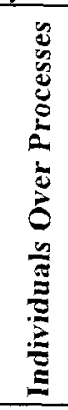 \\
\hline $\begin{array}{l}\text { 1. Non-flexible } \\
\text { empowered } \\
\text { workers }\end{array}$ & $\begin{array}{l}\text { Create an environment for } \\
\text { the individual to take re- } \\
\text { sponsibility (requires } \\
\text { leadership). Create bene- } \\
\text { volence. }\end{array}$ & $\begin{array}{l}\text { No } \\
\text { differ- } \\
\text { ence }\end{array}$ & Yes & Yes & Yes \\
\hline $\begin{array}{l}\text { 2. Too much uncoor- } \\
\text { dinated change }\end{array}$ & $\begin{array}{l}\text { Enough room for one } \\
\text { change at a time. An alter- } \\
\text { native approach would be } \\
\text { the active integration of } \\
\text { different change dimension } \\
\text { (see \# 4) }\end{array}$ & No & No & No & Yes \\
\hline 3. No clear IT vision & $\begin{array}{l}\text { Define and communicate } \\
\text { an IT vision and clarify } \\
\text { expectations. }\end{array}$ & No & $\begin{array}{l}\text { Yes, } \\
\text { indi- } \\
\text { rectly }\end{array}$ & No & No \\
\hline $\begin{array}{l}\text { 4. The organizational } \\
\text { change and the IT } \\
\text { infrastructure } \\
\text { development were } \\
\text { not well } \\
\text { coordinated }\end{array}$ & $\begin{array}{l}\text { Active integration of } \\
\text { organizational change and } \\
\text { IT infrastructure } \\
\text { development. }\end{array}$ & Yes & Yes & Yes & No \\
\hline $\begin{array}{l}\text { 5. The traditional IT } \\
\text { support does not fit } \\
\text { with the one-stop } \\
\text { shops that cut } \\
\text { across traditional } \\
\text { sectors }\end{array}$ & $\begin{array}{l}\text { A more modular under- } \\
\text { standing of municipal } \\
\text { service provision and } \\
\text { respective design of IT } \\
\text { support. }\end{array}$ & Yes & Yes & Yes & No \\
\hline $\begin{array}{l}\text { 6. Users had no } \\
\text { means to discuss } \\
\text { changes in the } \\
\text { infrastructure } \\
\end{array}$ & $\begin{array}{l}\text { Tools, techniques to design } \\
\text { IT infrastructure. }\end{array}$ & Yes & Yes & Yes & Yes \\
\hline
\end{tabular}


- Develop an IT vision in order to coordinate the development work in different sectors.

- Be prepared to rethink municipal service provision. The introduction of one-stop shops means more than the placing the interfaces to municipal administration and systems on the same desktop.

- New tools and techniques are needed to design (and develop) not only single applications but also a whole infrastructure consisting of such diverse applications as telephone exchange and access to mainframe applications.

The central politicians in Denmark have publicly declared that they expect a leap forward - the Minister of the Interior even called it a "tiger leap"--in the use of IT in government as a result of the Danish structural reform. One of our interviewees, Diana Dueodde, commented, "There may be a tiger leap waiting in the future, but it will not come at the same time as the structural reform." Our analysis seems to propose that the merging of several municipalities will force both the municipal organizations and the IT support to develop more agility. So the leap forward might be the ability to actively design the IT infrastructure together with the municipal service provision in reaction to policy changes and evolving citizen needs.

The analysis presented in this paper suggests that the design and development of IT infrastructures beyond the single piece of software or hardware is an important area for future research. As outlined by Bleek (2004) and Hjort-Madsen and Gøtze (2004), IT infrastructures rarely involve the development of new systems from scratch. Interoperability between IT systems and business processes is the key to creating onestop shops and we, therefore, need a better understanding of the management of these infrastructures

\section{REFERENCES}

Agile Manifesto. "Manifesto for Agile Software Development," 2001 (available online at http:/agilemanifesto.org; accessed October 12, 2004).

Aoyama, M. "Web-Based Agile Software Development," IEEE Software (15:6), November/ December 1998, pp. 56-65.

Baskerville, R., Levine, L., Pries-Heje, J., Ramesh, B., and Slaughter, S. "How Internet Software Companies Negotiate Quality," IEEE Computer (34:5), 2001, pp. 51-57.

Bleek, W.-G. Software-Infrastruktur-Von analytischer Perspektive zu konstruktiver Orientierung, Hamburg: Hamburg University Press, 2004.

Borum, F. Strategier for organisationscendring, Copenhagen: Handelshøjskolens Forlag, 1995.

Burnes, B. Managing Change ( $2^{\text {nd }} e d$.), London: Pitman Publishing, 1996.

Dittrich, Y., Eriksén, S., Ekelin, A., Elovaara, P., and Hansson, C. "Making E-Government Happen Everyday: Codevelopment of Services, Citizenship and Technology," in Proceedings of the $36^{\text {th }}$ Hawail International Conference on System Sciences, Los Alamitos, CA: IEEE Computer Society Press, 2003.

Dittrich, Y., Eriksén, S., and Hansson, C. "PD in the Wild: Evolving Practices of Design in Use," in Proceedings of the Participatory Design Conference, T. Binder, J. Gregory, and I. Wagner (Eds.), Malmö, Sweden: Computer Professionals for Social Responsibility, June 2002. pp. 124-134.

Dove, R. Response Ability: The Language, Structure, and Culture of the Agile Enterprise, New York: Wiley, 2001. 
Dunphy, D. "Organizational Change in Corporate Settings," Human Relations (49), 1996, pp $541-552$

Gerson E. M. , and Star, S. L. "Analyzing Due Process in the Workplace," ACM Transactions on Office Information Systems (4:3), July 1986, pp. 257-270.

Hjort-Madsen, K., and Gøtze, J. "Enterprise Architecture in Government: Towards a MultiLevel Framework for Managing IT in Government," in Proceedings of $4^{\text {th }}$ European Conference on e-Government, Dublin, Ireland, June 2004, pp. 365-374.

Kensing, F., and Munk-Madsen, A. "PD: Structure in the Toolbox," Communications of the $A C M(36: 6)$, June 1993, pp. 78-85.

Kotter, J. P. Leading Change, Boston: Harvard Business School Press, 1996.

Kotter, J. P. And Cohen, D. S. The Heart of Change: Real-Life Stories of How People Change Their Organizations, Boston: Harvard Business School Press, 2002.

Lenk, K., Traunmüller, R., and Wimmer, M. "The Significance of Law and Knowledge for Electronic Government," in Electronic Government: Design, Applications and Management, Ake Grönlund (Ed.), Hershey PA: Idea Group Publishing, 2002, pp. 61-77.

Newman, W., Podgurski, A., Quinn, R., Merat, F., Branicky, M., Barendt, N., Causey, G., Haaser, E., Kim, Y., Swaminathan, J., and Velasco, V. "Design Lessons for Building Agile Manufacturing Systems," IEEE Transactions on Robotics and Automation (16:3), 2000, pp. 228-238.

Paulk, M. "Extreme Programming from a CMM Perspective," IEEE Software (18:6), 2001, pp. 19-26.

Suchman, L. A. "Office Procedure as Practical Action: Models of Work and System Design," ACM Transactions on Office Information Systems (1:4), October 1983, pp. 320-328.

Weinberg, G. M. Quality Software Management, Volume 4: Anticipating Change, New York: Dorset House, 1997.

Yin, R. K. Case Study Research. Design and Methods ( $2^{\text {nd }}$ ed.), London: Sage Publications, 1994.

\section{ABOUT THE AUTHORS}

Yvonne Dittrich is an associate professor from Hamburg University. Her research interests are use-oriented design and development of software, codevelopment of work practice and software, end-user development, and eGovernment. Yvonne can be reached at ydi@itudk.

Jan Pries-Heje is an associate professor at the IT University of Copenhagen, Denmark. Jan holds M.Sc. and Ph.D. degrees from Copenhagen Business School. He is a certified ISO 9000 auditor and Bootstrap assessor, and has been project manager for a number of multi-media and IT-related change projects. From 1997 through 2000 , he worked as a consultant in IT quality and software process improvement. He is chairman of the Information Systems Research in Scandinavia (IRIS) Steering Committee, serves as the Danish National Representative to IFIP TC8 (since 1999), and is currently an associate editor for MIS Quarterly, Information Systems Journal, and European Journal of Information Systems. His research interests include information systems development, software engineering, and software process improvement. He focuses on organizational and managerial issues. Jan has published more than 100 papers in these areas in journals and conferences. He can be reached at jpr@itu.dk.

Kristian Hjort-Madsen is employed in the Danish Ministry of Science, Technology and Innovation. He is currently writing his Ph.D. on the management of IT infrastructures in the public sector in a public-private partnership program with IBM Denmark, KMD Denmark, and the IT University of Copenhagen. His research specializes in information systems mariagement and the use of enterprise architectures in public institutions. Kristian can be reached at khm@itu.dk. 